\title{
On the value of experience-based decisions in studying constructs of risk taking
}

\begin{abstract}
Eyal Ert*
Department of Agricultural Economics and Management, The Hebrew University of Jerusalem, Rehovot, Israel *Correspondence: ert@agri.huji.ac.il
\end{abstract}

Does risk taking behavior reflect intrinsic or constructed preferences? This question is deeply rooted in psychology and decision science, but is still the subject of a lively debate. The current paper suggests that the degree of support for the idea of consistent constructs of risk taking might be contingent upon the methodology used in the experiment. Specifically, it addresses the properties of two main paradigms that have been used to study this question: decisions from description and decisions from experience (Hertwig et al., 2004). The first paradigm attends to "explicit risk taking" extracted from self-reports of risky behaviors and/or tasks in which subjects are asked to choose between descriptions of different outcomes and their associated probabilities. The second paradigm deals with “implicit risk taking." It focuses on experiencebased tasks in which people make repeated choices between options without knowing their exact payoffs and probabilities. Instead, they have to learn them from experience.

Interestingly, while description-based studies typically find risk taking to be mostly situation-specific, experience-based studies show evidence of consistent individual differences, and seem able to distinguish populations associated with risk taking behaviors from controls. The current paper will first overview some evidence showing the difference between the paradigms in suggesting stable constructs of risk, and then will address properties of these paradigms that may contribute to the discrepancies.

\section{EVIDENCE FOR INDIVIDUAL DIFFERENCES IN RISK TAKING FROM DESCRIPTION-BASED AND EXPERIENCE-BASED TASKS}

Until recently, the search for stable constructs of risk taking has mainly focused on explicit tasks, such as self-report questionnaires and description-based tasks. The results from those studies, however, showed mainly individual inconsistencies (e.g., Schoemaker, 1990), suggesting that risk taking is mostly situation-specific. For example, it might be reversed, depending on whether individuals are choosing between gains or between losses (Kahneman and Tversky, 1979), it seems to depend on the exact response mode (e.g., choice vs. pricing, see Lichtenstein and Slovic, 1971), and it varies across different life domains such as financial, health, and recreational (Weber et al., 2002; Hanoch et al., 2006). Strikingly, even minor changes in the question format might reverse preferences among alternatives. For example, when people are asked whether they would accept a risky gamble that has a positive expected value they tend to reject it, yet when they are asked to "choose between" that gamble, and a sure zero payoff, they tend to prefer the gamble (Ert and Erev, 2008). These results might lead to the conclusion that behavior does not depend on stable individual constructs of risk taking; rather, it depends mainly on situational factors.

However, this conclusion seems inconsistent with another line of research that focuses on experience-based tasks. In these tasks, the risks associated with each option are not described to the decision maker. Rather, it is only through experiencing the different options that the individual can get a sense of what actions might be riskier. Two well-known examples are the "Iowa gambling task" (IGT) and the "balloon analog risk task" (BART). In the IGT, the decision maker repeatedly selects among four decks of cards. Each deck is associated with a gain but also a loss, sometimes a large one. Two decks have positive expected value and therefore are considered "advantageous." The other two decks are "disadvantageous" since they are associated with negative expected value. Decisions are made from experience: participants do not know the outcomes of each deck and have to learn them through realizing the outcomes of their selection following each choice. Initially, the IGT was found to be effective in differentiating individuals with bilateral damage to the ventromedial prefrontal cortices (VMPC) from control subjects (Bechara et al., 1994) ${ }^{1}$. This deficit was reflected in the task by higher selection of disadvantageous decks. Later studies showed that the IGT also seems useful in distinguishing control subjects from risk taking populations such as chronic drug abusers (Yechiam et al., 2005), prisoners (Yechiam et al., 2008), and traffic offenders (Lev et al., 2008).

In the second popular task, the BART, people pump "air" into a virtual balloon; each time they pump, a fixed sum is added to their account, but if the balloon pops before they cash out, they receive nothing. The common measure of risk is the number of pumps the subject tries before cashing out. Evidence indicates that the BART score could be a good predictor of self-reported unhealthy risk behaviors (Lejuez et al., 2002), and that it can differentiate controls from drug users and cigarette smokers (Lejuez et al., 2003).

The picture emerging from studies of the experience-based paradigm suggests that behavior is affected by stable individual differences that account for risk taking behaviors. Taken together, the evidence from the different paradigms suggests that the researcher's conclusion regarding the role of stable individual differences in risk taking might vary substantially according to whether a description-based task or an experiencebased task was used in the study. The next section suggests potential reasons contributing to the apparent discrepancy between the conclusions from the two paradigms.

\section{EXPLAINING THE DISCREPANCIES BETWEEN EXPERIENCE-BASED AND DESCRIPTION-BASED TASKS IN ADDRESSING INDIVIDUAL RISK TAKING}

Before addressing the different properties of each paradigm, it might be constructive to note that typical evidence from personality

${ }^{1}$ Ventromedial prefrontal cortices lesions are associated with a syndrome in which individuals have normal IQ and reasoning ability, but demonstrate excessive risk taking in their decision-making behavior. 
research suggests some support for both the situational and the individual trait views. Mischel and Shoda (1995) note that "the fact that the average cross-situational coefficients are typically low but non-zero is now widely accepted" (p. 247). Support for the effect of individual differences is suggested by the finding that the typical correlations across situations are consistently above zero. However, the large variation across situations suggests that situational factors may either mask such inherent tendencies, or at least interact with them in a way that results in apparently different behaviors (see also Weber and Johnson, 2008).

It is natural to assume that the role of situational factors will become more apparent when such factors receive more attention (e.g., when they are more salient). In description-based tasks, the situational factors are central and therefore are salient part of the description (e.g., the case of accepting/rejecting an attractive gamble vs. choice between sure zero and the gamble). In particular, they seem to be much more salient than in experience-based decisions in which the options are not described. Recently, Ert and Yechiam (2010) examined the possibility that individual differences in risk taking emerging from decisions from experience might differ from supposedly equivalent individual differences in decisions from description. Recall that a main finding in the decisions from description literature is the reversal of risk taking between the gain and loss domains, typically referred to as the "reflection effect." For example, while choosing between a sure $\$ 600$ and a gamble that gives equal chances of winning $\$ 1200$ or $\$ 0$, most people choose the certain amount. Yet, in a choice between a sure loss of $\$ 600$ and a gamble providing an equal chance of losing $\$ 1200$ or $\$ 0$, most people prefer the risky gamble (Kahneman and Tversky, 1979). Ert and Yechiam (2010) tested this prediction with a simple form of an experience-based task in which, instead of getting descriptions of the certain amount and the gamble, people chose repeatedly between two undescribed options, one that always yields 600 ( -600 in the loss problem) and another that yields either $1200(-1200$ in the loss problem) or 0 with equal probability. The authors found that the aggregate proportion of risk taking replicated the reflection effect, showing higher risk taking in the loss domain. However, the analysis of choice at the individual level showed a significant positive correlation of 0.63 between the gain and loss domains, contradicting the reflection effect. This observation suggests that people who prefer certainty in the gain domain also prefer certainty while choosing between losses. In another study, Yechiam and Ert (2011) gave participants descriptions of these same problems. The aggregate results once again revealed higher risk taking in choice between losses, consistent with the reflection effect. However, the analysis at the individual level showed no correlation between choices in the gain and loss domains. One interpretation of these results is that in the experience-based choice, the framing of gambles has only a small effect, so the tendency to take risks over certain payoffs emerges at the individual level. However, this tendency might be masked or canceled out by the saliency of the framing in the description-based task.

The observation that description-based tasks might be more sensitive to framing effects than experience-based tasks may possibly relate to Langer's (1989) notion of mindfulness vs. mindlessness. Mindful decisions are explicit ones in which the decision maker considers the properties of the problem. When the decision maker operates mindlessly, she tends not to think about the properties of the problem, at least not explicitly. It is natural to assume that experience-based decisions are more mindless than description-based ones. Interestingly, while intuition suggests that to extract individual differences one would possibly like to encourage the individual to think deeply about the task, evidence suggests that such thinking might actually bias the decision maker to consider irrelevant data. Therefore, the decision maker may be more likely to exhibit her inherent tendencies while acting mindlessly than while acting mindfully. Moreover, while operating mindfully, the decision maker might avoid (or approach) risks for a variety of strategic reasons that could also interfere with her inherent tendencies. In line with this argument, Koritzky and Yechiam (2010) found that experiencebased tasks are less sensitive than description-based ones to social-desirability effects. When participants were instructed to make a "good impression," they tended to avoid risks in description-based tasks more than under a control condition in which the instructions were neutral. Behavior in the experiencebased task, however, was unaffected by the instruction to behave strategically, perhaps because it is relatively hard to pinpoint the kind of behavior that is expected to make a good impression in such tasks.

Additional evidence supporting the existence of stable constructs of risk taking comes from studies in neuroscience, showing activities in brain areas that are related to risk taking. Interestingly, many of those studies seem to use experiencebased tasks in addressing the constructs of risk taking behavior. Some studies use the aforementioned IGT and BART (Rao et al., 2008; Lawrence et al., 2009), while others use different tasks that are also experiencebased in nature (Critchley et al., 2001; Preuschoff et al., 2006; Gianotti et al., 2009). This observation also suggests the potential usefulness of experience-based tasks in studying individual differences.

\section{CONCLUSION}

In a recent review of studies of individual differences in decision-making, Appelt et al. (2011) highlighted the importance of a standardized approach to studying individual differences, and the value of categorizing the existing measures into meaningful classes that share similar properties. The current analysis suggests that one such meaningful categorization is the differentiation between description-based and experience-based tasks. Evidence suggests that experience-based tasks tend to be more successful in revealing consistent individual differences than description-based tasks. A potential reason for this relative success could be that experience-based tasks involve more mindless than mindfulness decisions and thus they are less sensitive to the influence of situation-specific factors. The relative success of experienced-based tasks in addressing individual differences suggests reasons for optimism regarding our understanding of the role of individual differences in risk taking. The high variety of experience-based tasks that are currently in use seem to call for comparative evaluations of those tasks to better understand the contribution of each task beyond and above the others. Such analyses may facilitate standardization and could further clarify the exact constructs that the different tasks aim to address.

\section{ACKNOWLEDGMENT}

This research was supported by a grant from the Hebrew University. 


\section{REFERENCES}

Appelt, K. C., Milch, K. F., Handgraaf, M. J. J., and Weber, E. U. (2011). The decision making individual differences inventory and guidelines for the study of individual differences in judgment and decision-making research. Judgm. Decis. Mak. 6, 252-262.

Bechara, A., Damasio, A. R., Damasio, H., and Anderson, S. W. (1994). Insensitivity to future consequences following damage to human prefrontal cortex. Cognition $50,7-15$.

Critchley, H. D., Mathias, C. J., and Dolan, R. J. (2001). Neural activity in the human brain relating to uncertainty and arousal during anticipation. Neuron 29, 537-545.

Ert, E., and Erev, I. (2008). The rejection of attractive gambles, loss aversion, and the lemon avoidance heuristic. J. Econ. Psychol. 29, 715-723.

Ert, E., and Yechiam, E. (2010). Consistent constructs in individuals' risk taking in decisions from experience. Acta Psychol. (Amst.) 134, 225-232.

Gianotti, L. R. R., Knoch, D., Faber, P. L., Lehmann, D., Pascual-Marqui, R. D., Diezi, C., Schoch, C., Eisenegger, C., and Fehr, E. (2009). Tonic activity level in the right prefrontal cortex predicts individuals' risk taking. Psychol. Sci. 20, 33-38.

Hanoch, Y., Johnson, J. G., and Wilke, A. (2006). Domain specificity in experimental measures and participant recruitment. Psychol. Sci. 17, 300-304.

Hertwig, R., Barron, G., Weber, E. U., and Erev, I. (2004). Decisions from experience and the effect of rare events in risky choice. Psychol. Sci. 15, 534-539.

Kahneman, D., and Tversky, A. (1979). Prospect theory: an analysis of decision under risk. Econometrica 47, 263-291.

Koritzky, G., and Yechiam, E. (2010). On the robustness of description and experience based decision tasks to social desirability. J. Behav. Decis. Mak. 23, 83-99.

Langer, E. (1989). Mindfulness. Reading, MA: Addison-Wesley.

Lawrence, N. S., Jollant, F., O'Daly, O., Zelaya, F., and Phillips, M. L. (2009). Distinct roles of prefrontal cortical subregions in the Iowa gambling task. Cereb. Cortex 19, 1134-1143.

Lejuez, C. W., Aklin, W. M., Jones, H. A., Richards, J. B., Strong, D. R., Kahler, C. W., and Read, J. P. (2003). The balloon analogue risk task (BART) differentiates smokers and nonsmokers. Exp. Clin. Psychopharmacol. 11, 26-33.

Lejuez, C. W., Read, J. P., Kahler, C. W., Richards, J. B. Ramsey, S. E., Stuart, G. L., Strong, D. R., and Brown, R. A. (2002). Evaluation of a behavioral measure of risk-taking: the balloon analogue risk task (BART). J. Exp. Psychol. Appl. 8, 75-84.

Lev, D., Hershkovitz, E., and Yechiam, E. (2008). Decision making and personality in traffic offenders: a study of Israeli drivers. Accid. Anal. Prev. 40, 223-230.

Lichtenstein, S., and Slovic, P. (1971). Reversals of preference between bids and choices in gambling decisions. J. Exp. Psychol. 89, 46-55.

Mischel, W., and Shoda, Y. (1995). A cognitive-affective system theory of personality: reconceptualizing situations, dispositions, dynamics, and invariance in personality structure. Psychol. Rev. 102, 246-268.

Preuschoff, K., Bossaerts, P., and Quartz, S. R. (2006). Neural differentiation of expected reward and risk in human subcortical structures. Neuron 51,381-390.

Rao, H., Korczykowski, M., Pluta, J., Hoang, A., and Detre, J. A. (2008). Neural correlates of voluntary and involuntary risk taking in the human brain: an fMRI study of the balloon analog risk task (BART). Neuroimage $42,902-910$.
Schoemaker, P. J. H. (1990). Are risk-preferences related across payoff domains and response modes? Manage. Sci. 36, 1451-1463.

Weber,E.U., Blais, A. R., and Betz, N.E. (2002). A domainspecific risk-attitude scale: measuring risk perceptions and risk behaviors. J. Behav. Decis. Mak. 15, 263-290.

Weber, E. U., and Johnson, E. J. (2008). "Decisions under uncertainty: psychological, economic and neuroeconomic explanations of risk preference," in Neuroeconomics: Decision Making and the Brain, eds P. Glimcher, C. Camerer, E. Fehr, and R. Poldrack (New York: Elsevier), 127-144.

Yechiam, E., Busemeyer, J. R., Stout, J. C., and Bechara, A. (2005). Using cognitive models to map relations between neuropsychological disorders and human decision-making deficits. Psychol. Sci. 16, 973

Yechiam, E., and Ert, E. (2011). Risk attitude in decision making: in search of trait-like constructs. Top. Cogn. Sci. 3, 166-186.

Yechiam, E., Kanz,J.E., Bechara,A.,Stout, J.C., Busemeyer, J. R., Altmaier, E. M., and Paulsen, J. S. (2008). Neurocognitive deficits related to poor decision making in people behind bars. Psychon. Bull. Rev. 15, 44-51.

Received: 11 December 2011; accepted: 08 January 2012; published online: 25 January 2012.

Citation: Ert E (2012) On the value of experience-based decisions in studying constructs of risk taking. Front. Psychology 3:7. doi: 10.3389/fpsyg.2012.00007

This article was submitted to Frontiers in Cognitive Science, a specialty of Frontiers in Psychology.

Copyright $\odot 2012$ Ert. This is an open-access article distributed under the terms of the Creative Commons Attribution Non Commercial License, which permits non-commercial use, distribution, and reproduction in other forums, provided the original authors and source are credited. 